$1-1-2010$

\title{
Seeking Educational Self-Determination: Raza Studies for Revolution
}

\author{
Margaret E. Montoya \\ University of New Mexico - School of Law \\ Marcos Pizarro \\ Monica Nanez \\ Ray Chavez
}

Nadine Bermudez

Follow this and additional works at: https://digitalrepository.unm.edu/law_facultyscholarship

Part of the Law and Gender Commons, and the Law and Race Commons

\section{Recommended Citation}

Margaret E. Montoya, Marcos Pizarro, Monica Nanez, Ray Chavez \& Nadine Bermudez, Seeking Educational Self-Determination: Raza Studies for Revolution, 35 Equity and Excellence in Education 276 (2010).

Available at: https://digitalrepository.unm.edu/law_facultyscholarship/77

This Article is brought to you for free and open access by the UNM School of Law at UNM Digital Repository. It has been accepted for inclusion in Faculty Scholarship by an authorized administrator of UNM Digital Repository. For more information, please contact amywinter@unm.edu, Isloane@salud.unm.edu,sarahrk@unm.edu.

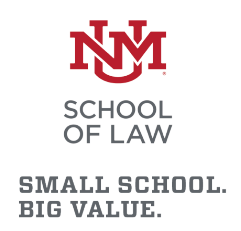

BIG VALUE. 


\title{
Seeking Educational Self-Determination: Raza Studies for Revolution
}

\author{
Marcos Pizarro and Margaret Montoya \\ with Monica Nañez, Ray Chavez, and Nadine Bermudez
}

\section{NOTE TO YOU, THE READER}

$\mathbf{T}$ his article is a multi-textured effort to explain the educational, social justice work of MAESTR@S,1 an innovative, organic group of educational activists fighting to address the needs of Latina/o youth. It is unlike anything we have ever written and probably unlike anything you are likely to read in an academic journal such as Equity \& Excellence in Education. We do not have a well-defined result that we are reporting to you. Instead, we see ourselves on a quest, with a deep concern about the current educational choices facing most $r a z a^{2}$ youth and their teachers, and a commitment to try to work in community with others who share these concerns.

MAESTR@S itself is also unlike other educational organizations. Our focus is on developing and demonstrating processes for engaging in revolutionary education. We are continually striving to eliminate conventional approaches to schooling and replace them with models that emerge from a new consciousness; one that many of us have not even fully imagined yet. This process of conscientizació $n^{3}$ is an integral part of the learning environment we are trying to create in our work and in this piece.

MAESTR@S demands a great deal of its participants and in this article we similarly demand a great deal of our readers. Because our work is completely processoriented $^{4}$ and grounded in the specificities of each context in which we find ourselves, it is difficult to translate into a written end product. In the workshops we coordinate, we seek subversion of the values and norms of conventional classrooms-teacher-centered, monocultural, irrelevant, objective and unconcerned with social justice-and disruption of conventional "education" and the passivity and conformity it demands and breeds. This article strives toward the same objective. We ask

Address correspondence to Marcos Pizzaro, 3251 Rustic Dr., Santa Clara, CA 95051. E-mail: pizarro@email.sjsu.edu you to commit to doing this difficult and even potentially disorienting work in reading this article since, in essence, we are asking you to participate in MAESTR@S. We recognize that some people who come to our encuentros are not able to do that. They prefer to be handed packaged templates and units for success. Those who invest and commit to the work, however, are able to create meanings and models that they can actually use immediately in all of their work. Asking you to commit to this kind of work, we believe, is the only way to model our work in writing.

We will try to explain some of this for you before you begin. Since this is the only section in which we focus on the process of reading our work, we suggest that you return to this introduction whenever you might feel out of sorts during your reading. Our approach requires that we break with several conventions of academic writing. To begin with, we obviously are speaking directly to you as an active reader. In doing so we are trying to take the covers off the process in which researchers traditionally engage. Typically, educational research is objective and follows specific conventions. For example, researchers must not be biased in their work and they therefore often write about their work as if they are re-telling a discussion of facts they heard someone else telling. The reality of course is that researchers are deeply committed to their work and intrinsically biased toward their chosen methodology, analytical framework, findings, and the meanings they attach to them. The difference in our approach is that we make this clear and do not hide our investment in this work behind a veil of academic distance.

Second, we do not use a multitude of sources to validate the ideas covered in this article. We know that these ideas stand on their own, as we have seen their power and value many, many times and have had them validated through dozens of interactions with students, teachers, youth workers, parents, and elders. ${ }^{5}$ Another way we have come to understand this is through something our elders have taught us: Our bodies have all of 
the answers, but in order for us to tap into them we need to unlearn the "education" that has taught us to distrust ourselves. ${ }^{6}$

Third, there are many concepts that we consider fundamental to our work, such as revolution, raza pedagogy, raza wisdom, raza ways of knowing or epistemology, educación. For all of these, we provide general definitions so the reader can understand how we locate them in our work, but we also recognize that many of these terms have multiple meanings not only to us, but to our participants and to you, and within each of the unique contexts in which our work is eventually applied. In the end, our model demands that we enable our readers to join us in making meaning and giving life to the work as it will be lived in your own work as readers and teachers.

We recognize that some of our participants and readers are much more familiar than others with the work upon which we are building, so that we ask those who know less about this work to catch up quickly, by sticking with us, by recognizing that not knowing and entering a new world can be discomforting but also ripe with educational possibility, by looking for other readings, and by looking for mentors in areas that are new. This effort on the part of our readers is similar to the work we often ask participants to do in our meetings. Our work demands some shared understandings, but many of our participants have developed this shared understanding as part of the process of our work.

We consciously make assumptions-just as the mainstream makes assumptions under the guise of meritocracy about what raza youth "need to know" as the foundation for their learning and what they need to do in order to earn "success." We are not simply making assumptions but saying that we need to make certain assumptions because that allows us to transcend the world in which educational activists typically spend most of their time responding to the mainstream in efforts to convince those unfamiliar with their ideas. This is a tremendously powerful, necessary, and complex idea. It is also one that is understood only as part of the MAESTR@S process. The process can be uncomfortable, but as you will see, this discomfort is an important part of the radical work raza youth require (not to mention a big part of their experiences in schools). We hope that this makes sense at the end of your reading/work, but we also recognize that, like all unconventional education, the lessons can come in waves and often only after the experience (the reading in this case) is over.

The article does not always follow the conventional order in which research is typically presented. Again, we ask our participants to surrender to the process in which we engage together. We also expect you to engage in this work in different ways. Some readers may need to work on one section of this article intensely, while others may understand that same section quite easily. Some of you may cut directly to the third section for our model, only later to return to the earlier sections of the article. All of our work (like this piece) is holistic and demands immersion into the entire process.

We begin the article by setting the context for our work: evoking images, feelings, and experiences that we have found widely shared among raza youth. We believe that if you are not aware of and committed to addressing this reality, the rest of our work is irrelevant. The first section provides you with this backdrop, but with little direction as to what you can do with that information.

In the second section, we provide an explanation of how this fits into our work as we begin to cover some of the key constructs behind our work. We also explain MAESTR@S in depth as we describe our history and objectives and demonstrate some of our past work. We spend a significant amount of time looking at our Summer Institute because it helps the reader live some of our work. Finally, in the third and last section, we end by defining our work more concretely through the description of our evolving model and ethic.

Our goal is for you to understand the work MAESTR@S does in a complex way by the time you finish the reading/work, but also that you be able to adopt/adapt some of our approach in your own work and begin to help us continue to develop this work. As we explain throughout, our work and model will always be evolving and we know it will move in new directions even by the time this work goes to press.

\title{
SETTING THE EMOTIONAL AND INTELLECTUAL CONTEXT
}

\author{
For Miguel: $\operatorname{Marcos}^{7}$
}

i'm a 6th grade teacher, it's 1991, and Miguel Sanchez is going down. He's going down brothers and sisters. going down.

dan dallape, the Vice Principal of Oak Street Elementary School on the West Side of Inglewood, Califas, a working-class community of raza, has made it his personal mission to take Miguel Sanchez down, because ... . [despite the litany of district-sanctioned reasons he claims] 
Miguel is learning his own power

Miguel scares him

the only way to stop the revolution is to suffocate the spirits of our youth, and so Miguel Sanchez is going down.

He's going down ...

we feel it, and complain about the schools—somethin' just ain't right

we see it, and complain about teachers-hate in their eyes

we smell it, and complain about counselors-decay hanging in the air

we hear it, and complain about administrators-insults framed as 'what's

best for them'

we taste it, and complain about "the system"- the metallic flavor of the blood on

our own hands

and Miguel Sanchez is going down.

He's going down,

and we watch,

all of us, watch ...

10 years later, too long, MAESTR@S asks us: What are we going to do about it?

concretely, what are we going to do about it?

everyday, what are we going to do about it?

we are a pro-active effort to make sure

Miguel Sanchez does not go down!

because if He does, if She does

$\rightarrow$ the assault on our young women is just as overwhelming

if They go down,

We all go down brothers and sisters

We're all going down ...

wake up

[note: the names have not been changed because we must speak truth]

\section{Hearing Voices, Seeing Ghosts: Marcos}

Cynthia Juan Jawicidi Mayra Kyara Cristina Ben Elizabeth

Lamisha Karl Gerardo Tomasa Sonia Victoria Dung Omar

Nelson Jaime Frank Monica Sheree Griselda Chevy Manolo

Erik Olga Daniel Cesar Antonio

Iliana Maria Emerson

I am looking at a picture: "Mr. Pizarro's 6th grade class, Oak Street Elementary School, 1990-1991."Smiling faces.

- I remember their stories: Nelson told me about his grandmother, a Maya Indian, who could cure anything.

- I remember the things other teachers had said about them: One teacher told me Emerson was nothing but a troublemaker and urged me to make an example of him. Emerson later proved to be one of the brightest kids I ever worked with.

- I remember their 11- and 12-year-old dejection: When they first entered our classroom, so many of them had already learned to tune out of school because it was not for them. That was the one lesson the school had hammered home.

- I remember their hope: I later taught kindergarten and was so overwhelmed by the excitement and eagerness of those 5- and 6-year olds. They loved school and yet many were the younger sisters and brothers of the dejected I had seen down the hall only months before.

Like ghosts, they haunt me and I hear their voices asking me to remember; to think like them. 


\section{Reality and Schooling}

Marcos: "School sucks!" When I do think like the kids in that class, over 10 years ago, these are the words that come to my lips. "School sucks!" I know this from looking in the eyes of raza youth. Their eyes tell anyone who is willing to look into them-not past them. They say, "This is a big waste of time." The further up the educational food chain we move, the more reasons we come up with as to why the kids are wrong. Then there comes a point when we forget that they can even speak. We know that they can make noise, but the possibility that they have voices and insights and power has been removed from our consciousness. The reality of schools is the one that exists within the minds and daily lives of our youth. When they are given the chance, they make the message both clear and irrefutable. School sucks!

In late March 2002, I attended a meeting organized by local youth, most of whom were raza, in which they provided compelling research to make the case that school does suck. They demonstrated how the California high school exit exam is both racist and blames the victims for the shortcomings of the schools. They showed how their teachers were ill-equipped to work with the dynamic and diverse student population in their schools. They resisted the popular belief in schools that students who first learn a language other than English have a handicap. They are now pushing for a school certificate to acknowledge the tremendous achievements of bilingual students. They lambasted the district for not preparing them for college-two-thirds of them do not complete the requirements for entry into the state universities. They demonstrated the dramatic difficulties they face in preparing for college without access to counselors. The problems the students are fighting against are most clearly demonstrated through one simple figure: While raza make up $40 \%$ of the students in these schools, they are over $60 \%$ of the dropouts and less than $20 \%$ of those graduates eligible to attend the state universities (Californians for Justice Education Fund, 2001).

These students, their stories, and their powerful critiques are whyMAESTR@S does what it does. We try to think like them before we think for us.

Margaret: Many students, especially students of color, arrive at law school intending to develop new tools for helping their families and communities. They long to engage in discussions about how the law is experienced as an instrument of oppression in the barrios, inner cities, and small towns through the impersonal bureaucracies of welfare offices, immigration procedures, school systems and the criminal justice system. These students assume that law school will provide an education about inequalities and injustice. Instead law school-like much of higher education-is designed to make students comfortable with the idea that they will spend the rest of their lives working in jobs that maintain the status quo and support the current arrangements of power. Students emerge from law school (or medical school or graduate schools) with considerable debt from the loans that pay for their tuition and living expenses. They have not been educated to provide services to the poor and working classes who can hardly afford to pay for legal or other social services. Moreover, students often emerge from law school with little understanding of how the law maintains inequalities based on race, language, or citizenship. Thus, students face considerable barriers if they plan to represent juveniles charged with crimes, immigrants trying to regularize their INS status, women involved in domestic violence, or families whose children have been pushed out of schools.

There is a connection between Marcos' students in elementary schools and the inadequate education of students in higher education. The schools in this society from K-12 through postgraduate are not designed to support deep social change. High drop-out rates, bored and disillusioned students, unchallenged and unprepared teacher education students, and debt-ridden law students are all part of the same continuum.

As this first section demonstrates, this article abandons conventions and seeks to enact the work MAESTR@S does. While it is impossible to expose the complexity of our work in words alone, this article, like otherMAESTR@S work, seeks to perform the theories that grow out of radical scholarship, and it represents our strongest effort to live the MAESTR@S approach to education in our writing. The article exposes our own efforts to achieve intellectual sovereignty and strives to model the way in which we can engage in revolutionary education. It is not a traditional research article because it challenges the effectiveness of that approach. Instead, it is improvisational story-telling in the tradition of raza ways of knowing. It strives to speak the way both youth and elders tell us we need to speak. We interject stories as their importance emerges in our own understanding of our work.

\section{MAESTR@S: KEY CONSTRUCTS, BACKGROUND, AND PRACTICES}

MAESTR@S is an experimental collaboration among educators and activists who are impatient with change that is promised in the future. MAESTR@S brings together K-12 teachers and parents with college and professional school teachers and researchers to develop strategies that can interrupt power arrangements in the classroom in order to enable students to acquire the knowledge and skills they need to have greater control 
over their own lives and to improve conditions for their families and communities.

\section{Moving Beyond the Reactionary Tendencies of Educational Activism: Marcos}

MAESTR@S emerged because we need something different-different books, different curricula, different teaching, different schooling. I could see this very clearly as a student, then as a teacher, then as a researcher, and finally as a professor.

The problem I encountered for the vast majority of my 30 years in the schools is that no one knew how to do things differently. Perhaps they chose not to. Regardless, I have seen very clearly how schools breed conformity of thought and action. We never learn how to question the basic assumptions that continually limit us because those assumptions are understood as norms rather than as limitations.

MAESTR@S evolved as an effort to help raza empower themselves in the schools, but outside of a mainstream perspective. We wanted to completely re-think how we approach schooling. As we later realized, we were, and we are, seeking sovereignty of the mind! ${ }^{8}$

For us, sovereignty of the mind means having control over our own thinking. We argue that our minds are often occupied territories, inhabited by dominant paradigms and ideologies that create a racist and oppressive logic that seeks control over our daily lives in the U.S.- making us comfortable with racial injustice, for example. For instance, today in California raza make up less than $10 \%$ of the students in the best schools (those ranked in the highest 10\% of all schools). Raza, however, make up over $75 \%$ of the students in the worst schools (those ranked in the lowest $10 \%$ of California's schools) (Wells, 2001). These figures represent a shocking degree of inequality. Very few people, however, are standing up to challenge this injustice; many think it upsetting, but natural. Sovereignty of the mind would allow us to see the world as it really exists in our daily lives from a raza perspective, and not as we are told to interpret it by the mainstream. Rebellion rather than passivity becomes our logic.

This sovereignty requires not just changing the rules, but erasing the old rules from our consciousness to create new models from new spaces. In U.S. schools, for example, most students understand education as competition between individuals with winners and losers. Evidence of this can be easily found in the high-stakes standardized testing used to demonstrate student and school winners and losers, and which even determine who graduates and who fails.

By seeking the sovereignty of our minds, MAESTR@S is challenging the most basic U.S. educational assumption-the idea of meritocracy-and replacing it with the lessons from raza wisdom and raza ways of knowing. These are very simple ideas and yet very difficult to understand, simply because they exist in direct contradiction to the educational norms under which we live. Some of the earliest work to lead us in this direction is the analysis of the "funds of knowledge" in raza households that should be tapped into within schools (Gonzalez et al., 1995). Valenzuela's (1999) analysis also is helpful as she identifies the problems we discussed previously and frames them within the concept of "subtractive schooling" to describe the ways in which schooling "divests [Chicana/o] youth of important social and cultural resources leaving them progressively vulnerable to academic failure" (p. 3). Valenzuela challenges the process whereby the complex understandings of educación within the raza community are squeezed out of raza students and replaced with a simplistic "American" model of education that not only ignores, but cannot begin to understand, the power of the intricate knowledge and cultural systems that enable these youth. Valenzuela defines "educación" in Chicana/o and Mexicana/o communities as, "the family's role of inculcating in children a sense of moral, social, and personal responsibility [that] serves as the foundation for all other learning" (p. 23). It is "a foundational cultural construct that provides instructions on how one should live in the world" (p. 21).

There also is new research largely done by scholars of color that examines power arrangements in this society and seeks to create new possibilities for greater equality (Delgado \& Stefancic, 1998; also see www.LatCrit.org for information on an ongoing collaboration of educators focused on legal issues).MAESTR@S seeks to use the insights of such research but at the same time we resist the constraints imposed on educators through such conventions as monolingualism, research protocols, or disciplinary jargon.

MAESTR@S challenges educators to look at their own experiences, to look at their students' unique characteristics, and to look at practices and daily life in raza communities so as to unpack raza ways of learning in their own contexts that can be applied to their teaching. We suggest that some of the key principles behind raza ways of knowing include the beliefs that knowledge:

- is subjective and dynamic rather than objective and linear,

- is passed on through the elders who represent our cultural legacy, rather than through "legitimate" histories,

- is communal and shared for the benefit of all, rather than an individual possession used to achieve solitary success, 
- emerges from our families and must always be connected to our obligations to our families and their legacies,

- provides an alternative way of understanding how we are different from the dominant society (in beliefs and values, ways of expression, etc.) and why such differences can be indicators of learning proficiencies and a source of strength for students, families and communities.

MAESTR@S, therefore, believes that raza ways of knowing can become the foundation for innovative approaches to helping raza youth empower themselves through their schooling. This work is grounded in the notion that there are raza pedagogies, or ways of teaching, that prevail in our communities and that can be used within schooling. Again, we do not presume to know the entire spectrum of raza ways of knowing and teaching but rather attempt to expose individuals to these ideas and seek their help in finding ways to engage in revolutionary education that challenges and then replaces U.S. schooling norms.

Educational revolution begins with breaking into people's consciousness. When we are able to liberate our minds from the constrictions imposed by the norms of schooling, then we can be creative and will know how to begin to look for and tap into the resources and people who will help us develop revolutionary approaches to our own work. This is MAESTR@S' primary objective: to provide people with the skills, support, and confidence to attack dominant U.S. educational ideologies and to achieve a new consciousness grounded in raza ways of knowing/learning/teaching.

\section{MAESTR@S History: Marcos}

I understandMAESTR@S as an organic entity that began as an idea, incubated for a period of time, and eventually led to the birth of a formal organization. This organization, however, is still developing and changing as it responds to the many needs of raza youth, their families, communities, and teachers.

MAESTR@S was born out of the frustration of a new generation of raza, educational activists. While the gains of the educational activists of the 1960s had inspired many of us, we found ourselves frustrated by the lack of ongoing, educational organizing efforts that addressed the persistent failure of the schools to allow raza youth to educationally empower themselves. Even in radical spaces like the National Association for Chicana and Chicano Studies (NACCS), most people concerned with these issues were working individually and oftentimes in very conventional ways.

I publicly expressed this frustration to members of NACCS as well as to other raza I knew and asked those interested to participate in a workshop in which we would talk and strategize about engaging in educational revolution with the goal of coordinating our efforts. It would be an opportunity for truly collaborative educational organizing and resource-building. No one would speak for more than a few minutes. We would take advantage of all the powerful people we might attract and use them to create spaces for something different. Although I did not yet know it, that was the birth of MAESTR@S.

People who participated in that first workshop at the NACCS conference in the spring of 2000 wanted to continue working together as resources for each other and to develop something larger. Our next larger meeting occurred in the fall of 2000 in San José, California where we defined the educational issues we were facing as well as the influences behind these "problems." In retrospect, what was most important was that we created our organizational agenda with the input from all those who attended. By starting with the shared understanding that raza youth require educational revolution to meet their needs in the schools, and by tapping into a diverse and dynamic group of committed educators, we developed an agenda and goals that were complex and grounded in the realities of our participants' day-to-day work. This led to the creation of a mission, general goals, and more specific, long-term goals (see Appendix A).

Further meetings enabled educational activists to share innovative approaches to working with raza youth and began the process of creating a community engaging in this revolutionary educational work. We learned that we must start with transforming the ways we ourselves think about schooling. Our meetings attract a diverse group of teachers, activists, youth workers, faculty, and community members, but they all are looking for someone who speaks their language. They are looking for someone who acknowledges the need for fundamental change in schools and who seeks new ways of engaging raza youth in radical education. For this reason, we have focused our work, at this early stage in our existence, on developing a model that replaces standard schooling practice. The first step of this work is to attack the way we have learned to think about schooling.

\section{MAESTR@S Lived: Examples of Revolutionary Practice}

Marcos: Before describing the model we are developing, we must first provide some examples of how we changed our own thinking. In November of 2001, at our fall meeting, Jenny Beltran-Lopez and Lorena Montoya (from Cihuatl Olin Nauhcampa) presented their latest work. ${ }^{9}$ They transformed our meeting place by 
developing five different educational centers for us to work at. They assigned us to the centers and sent us off to do the assignments they ask their own students to do. We became busy little elementary students designing pyramids, studying masa under microscopes, reading and working on creation stories, learning Mayan math systems, and analyzing the ways in which maps have changed over time. The room was alive in ways that many classrooms rarely are. In one group, a community organizer, a high school student, a university professor, and a high school teacher all shared discoveries, insights, questions, and themselves. And for the rest of the day people kept on telling me how much they got out of that experience. As one of our camaradas explained,

I was truly enlightened by everyone's innovative, creative, revolutionary, radical, raza-centered input on educational curricula and technique. Lorena and Jenny proved MAESTR@S praxis masterfully. I learned how every subject can have a cultural connection (Anonymous evaluation from MAESTR@S Fall Encuentro, 10 November 2001).

The mujeres in Cihuatl Olin provide a powerful example of the way in which MAESTR@S' work has very real and practical applications. Using the MAESTR@S encuentros as a testing ground for their work, these young teachers and college students developed units based on the medicine wheel and using indigenous beliefs, history, architecture, science, math, and the arts to cover the mandated grade-level standards in $\mathrm{K}-2$ classrooms in the State of California. Building on the freedom fostered by theMAESTR@S approach, they have designed curricula that are grounded in raza funds of knowledge and that provide children with the skills they need to thrive in the school system by honoring their histories and stories. Not only is their curricular work revolutionary but their practice is completely student-centered and, as we experienced in their workshop, liberating. In the workshop, for example, we participants were ourselves empowered to see our ancestors as philosophers, artists, scientists, engineers, as thinkers. Not only that, we also were fully engaged in the learning process: mentally, physically, emotionally, spiritually, and historically. What is most powerful about the work of Cihuatl Olin is the fact that they have done it all entirely themselves without funding or other forms of institutional support. Sharing our radical educational consciousness, they suggest not only that educational revolution is possible but that it is happening.

Margaret: Teaching about race and racism within law schools can often be a disheartening task. Soon after arriving at law school, students learn to focus on their professional careers and to worry about getting jobs. Law firms and other employers don't hire stu- dents who show an interest in intellectual sovereignty or revolutionary change of any kind. Students report to me that they are reluctant to take courses that may tip off their potential employers about their political views. Try to imagine an environment in which taking a course about social change takes moral courage.

In the spring of 2001 I offered a new seminar called "Lawyering for Social Change: Writing for K-12 Teachers and Students," for students to use legal work to develop curricular materials for teachers working with students of color. Students experimented with new technologies such as PowerPoint software, the Internet as a learning resource, $\mathrm{CD}$ and zip drive formats and to research and write about topics of their own choosing. I wanted to create a learning environment in which the students felt free to take charge of their own learning and combine their creativity and imagination with what they were learning about legal rules and procedures. I wanted to create a learning space that contrasted with the coercive and hierarchical characteristics of the typical law school classroom. I didn't know it at the time but I was already leaning towards the MAESTR@S pedagogical model.

Four students enrolled for the seminar, most of whom felt alienated from their studies and harbored thoughts of leaving law school altogether. The students were racially/ethnically, geographically, and otherwise diverse: Linda Lang is an Alaska native single mother, Charmaine McDarment also is an indigenous woman from one of the California tribes, Peter Phipps is a mixed race, Japanese-American raised in Southern New Mexico, and Mike Richardson is a White man with a degree in pharmacy. It was curious (and deeply disillusioning to me, if I am candid with myself) that, in a school with approximately 30\% Latina/o students, no Chicana/o students enrolled for a seminar focused on writing for K-12 teachers involved with Latina/o students.

The chemistry of this seminar worked; the atmosphere of the class was intimate and informal, with demonstrations of curricular materials, discussions about my current research on the racialized aspects of language such as silence or about my organizational activism on affirmative action, and sharing ideas among students about their sources and organizing approaches for their projects. The classes were informal discussions that created a strong bond and a feeling of intimacy among us. Charmaine was our "technology guru" and with her ease with the computer taught us how to use PowerPoint and other tools but also taught us that an indigenous woman can be thoroughly modern even as she prepares to work for the interests of tribal peoples.

Each student chose a topic that had both racial and legal dimensions: Lisa chose Indian stereotypes and 
examined Disney characters, traditional Thanksgiving celebrations, and sports mascots. Charmaine researched the border region between the U.S. and Mexico, the free trade regime and its effects on water and air quality, and the Mexican maquiladoras. Peter focused on the Chicana/o youth movements of the last decades including their artistic and political representations. Finally, Mike looked closely at the "war" on drugs and why militaristic metaphors have been used for this failed public policy. The students worked on their materials with the goal of "rolling out" their finished products towards the end of the semester. The finished materials completely exceeded my expectations-they were sophisticated in their treatments of legal topics and appropriate for teaching about race to students at different educational levels. We met and surpassed the formal objectives I had set for the course. More importantly, we created a humane learning environment in which we developed talents and skills to improve conditions for others.

This hope can only be realized if the experiences of this law school classroom and others like it are part of a larger process. Law students like Lisa, Charmaine, Peter, and Mike will work exceptionally hard and retain their interest in law as an instrument of social justice once they know that their efforts will resonate in other spaces and places. This is the promise of MAESTR@S, that we can create new synergies through our collaborations and free our classrooms, wherever they fit on the educational continuum, from the constraints imposed by power hierarchies, resource inequalities, and outmoded conventions.

On the last day of our MAESTR@S Summer Institute, I shared this work and it blew people away. The law students' materials combined powerful images, text, and music and were designed to provide youth with the opportunity to develop critical thinking skills that address both their own lives and the damaging messages they are force-fed through the media and the educational system. The students' projects looked at issues like the Chicana/o movement and the war on drugs, but what was most powerful about it was how do-able it was. Here was the beginnings of a model that university professors could use anywhere, and one that, when linked to the specific needs of high schools, could radically transform the work of raza youth in the schools.

Marcos: The power of this work is not that individuals learn the content for a specific raza-centered curricular unit or even that they observe a particular teaching technique. Instead, we try to create a climate in which the dominant educational ideologies no longer exist and where a new logic is created for raza education. This allows us to develop a culture and support system in which revolutionary ideas breed. I again realized the importance of this when Lidia Reguerín approached me at the end of our gathering in November of 2001,10 and said that in the 20 years since she graduated from the Stanford School of Education, this was the first professional development opportunity that she actually liked, where others spoke the same language as she. She was referring to a language of revolution for raza youth. To me, she was also speaking of the new, collective consciousness that we attempt to establish as the foundation of our work.

\section{Facilitating Revolutionary Education: Margaret and Marcos}

MAESTR@S has become a collaborative effort facilitated by the two of us. It is a natural partnership but unusual. Margaret is a Chicana from New Mexico, a lawyer and law professor who was part of the generation that busted down walls of exclusion in academia. She has done contemporary work in legal scholarship, transforming the way in which we understand the law and its oppressive aggressions toward raza. Marcos is a California Chicano, a former schoolteacher, who works on issues related to Chicana/o youth identity. He is part of the new generation of Chicana/o scholars who have benefited from the trails blazed by earlier generations.

We are both deeply committed to using our academic work to seek social justice. In particular, we want to transform our classrooms into sites (and sights) of resistance in which we continually challenge all of the rules of the schooling game. In the end, our trust is complete and we surrender ${ }^{11}$ to each other, knowing that together, we can push educational boundaries in ways not possible alone. And so we came together to coordinate a 3-day "training" based on our commitment to transform schooling for raza youth, even before we had consciously mapped out our own educational model.

Our basic, shared idea for this 3-day Institute was to model educational revolution rather than to "teach" radical education. It is based on a simple, Freirean idea that recounting the radical thoughts of others is not, in fact, radical education. Radical education is putting learning in the hands of the people and letting them use it to meet their own needs (Freire, 1970). We asked workshop facilitators to model their work for us in specific sessions, thereby suggesting that modeling was our content. In turn, we spent a lot of time designing the specific tactics we would have to use to model revolutionary education as we did the often-transparent work of facilitating. The other major component of the Institute was that we asked the participants to form into groups and work together over the three days to produce something useful to their own work by the time we ended. 
Margaret and I were both overwhelmed at how well the Institute came off. What we had done was to implement an educational model that was in fact revolutionary. Furthermore, it was one that we could reproduce (although never with the same results, of course).

The best way to provide a more complete understanding of MAESTR@S' work is to describe our Summer 2001 Institute. Rather than providing a traditional start-tofinish description, however, we will focus on key issues that best describe MAESTR@S.

\section{Summer Institute, Late June, 2001: Margaret and Marcos}

Margaret: I flew into San José a day early for the 3-dayMAESTR@S meeting so that Marcos and I can kick around some ideas. We never really develop a plan; we know enough to let the process emerge out of the moment. Marcos has invited me to stay at his home with him, Esther, his wife, and their two young daughters. This is to prove to be an important decision, allowing me to talk with Marcos as we drive in and back at the beginning and end of each day. The drive time creates a space for us to debrief each day and to replay for one another what has worked and what has not. This drive time gives us a chance to focus the conversations so that by the time we arrive, the conversation involves Esther who offers a nonparticipant perspective to the issues we identify at the end of each session. My staying at Marcos' home foregrounded issues of familia, comida, playtime, and raza hospitality.

I had attended three of the five earlier workshops that Marcos had organized. There was an ease that I felt with him that signaled to me that we could do this team facilitation and do it in a way that modeled certain values and sensibilities. For one thing, I was able to make race- and gender-conscious comments and Marcos responded with what I think of as conscientizacion. But there was more. At one of the earlier workshops, I had been demonstrating some of the techniques I use to involve students in class discussions. I turned to Marcos and asked him to repeat what the previous "student" had said before asking his question or adding his comment. Marcos was caught off guard. I explained that I wanted him to listen not only to me "the teacher" but also to the other students since we were all teachers and learners. Later, Marcos was to retell that incident explaining that he had incorporated it and other techniques we had demonstrated into his undergraduate teaching. I sensed from this that we could develop the ability to use one another as props in our teaching exercisesprops in the most positive sense. Being a team of a prop and a prompter required that both of us think through the teaching technique, name it and, when possible, improve upon it. That was to be the secret of our team work.

Marcos: This secret ingredient has been powerfully supported in our work by the fact that we are both very process-oriented. We both see the actual content of our teaching/workshops as a very small part of our educational work. Much more important is exposing the inner-workings of education work to unpack the way in which dominant ideologies define the assumed building blocks of schooling. This was demonstrated in an event that became the centerpiece of the Summer Institute.

Marcos \& Margaret: The Summer Institute was a 3-day encuentro that focused on how to engage in revolutionary educational work with raza youth. There was a wide array of teachers, people who worked in professional development for teachers, others who provided social services to youth or worked in youth programs, and university faculty and students.

On our way home from the 2nd of 3 days of the MAESTR@S Summer Institute, we came to the conclusion that we had to begin our 3rd day differently. We had opened the first day with an indigenous ceremony that acknowledged the four directions, the four elements, and called on our ancestors to help us with our work. This ceremony ended with a circle in which everyone was given the chance to share words. One of the elders from Arizona explained that she wanted to say the "Our Father" with the group. Some felt this was helpful, but others felt affronted, given the historical tension between Catholicism and the indigenous peoples of the Americas. On the second day, it happened again, as the person requesting "Our Father" also moved out of the circle and stood next to the leader of the indigenous welcoming ceremony. The tension was thick and several participants approached us that day to discuss this.

Our educational model is grounded in the necessity of addressing the issues being faced by the group. So when this tension arose around the welcoming ceremony, we felt it was irresponsible to ignore it. That next morning we explained that there had been some significant tension during our daily openings. We asked people to comment. Their responses were respectful and they avoided the issue. We had done amazing work in those first two days and, as we began to realize that last morning, people didn't want anything to negatively affect the good feelings they had about the group and the work we were doing. We tried again, but the avoidance continued. The group resisted addressing the tension and then some became upset that we were even raising the issue and frustrated that we were focusing on that instead of the agenda we had laid out... 


\section{Time Out: A Dialog on Chicana/o Indigenismo}

\section{Margaret:}

This ceremony challenged Marcos and me for different reasons based on our regional and generational perspectives: I am from New Mexico, he's from California; I am a child of the $60 \mathrm{~s}$, he of the 80s. Differences among raza are grounded in our different histories, cultural traditions, and the strength of our connections to México and other parts of America Latina. I have been working closely with a colleague from the Isleta Pueblo whose academic work includes indigenous identities. Thus, for me, Chicana/o claims to indigeneity have different meanings than for Chicanas/os from California. My New Mexico ancestors identified as Hispanas/os and not as indigenas/os. On these points, Mary Romero (2000) has written that "[a] serious confrontation with our mestizo heritage is a complex project [that] include[s] accepting historical responsibility and recognizing privileges gained by neither being fullbloods nor assimilating into Spanish/Mexican culture. ... While I recognize that the spirituality gained may be inspirational to some individuals, the imagined community is thoroughly exclusionary ... [and can be] an obstacle to coalition building within and outside Chicana/o and Latina/o communities" (pp. 16151616).

As an act of solidarity with the group, I did not voice my reservations about the contradictory meanings of the ritual nor about the need to acknowledge the history of conquest and exploitation implicit in the Catholic prayer. I took the role as facilitator and not dissenter. I now add my concerns about the ritual in a spirit of group self-critique in the hope that we can consider these complex issues at some future time.

Marcos \& Margaret: Some participants were resentful that the addition of the "Our Father" had bothered anyone, and others wanted us to get back to the schedule. The tension grew for about half an hour as these dual frustrations built for many. Seeing both that we were getting somewhere and that the tension remained, Marcos explained exactly why this was so important to us.

As teachers, we do not have the luxury to ignore the issues our students bring into the classroom. If we do, we lose them. They tune out, lash out, or simply fade away while we focus on our lesson plans. The difficulty, of course, is finding ways to ground our students' experiences and concerns in educational work so that we can keep pushing them.

As people began to open up more and deal with their feelings, the mood changed. It became a forum for releasing those feelings and tensions. It became a chance
Marcos:

The inclusion of the indigenous-influenced welcoming is something that has emerged as a response to needs identified by many of our younger members. The issues Margaret raises are very important, and Romero (2000) speaks to some of the biggest contradictions within Chicana/o indigenismo. For me, the ceremonies we have included speak to two of the issues that our Native American sisters and brothers have raised with us. First, some have questioned the common Chicana/o erasure or ignorance of our indigenous heritage, which some even interpret as self-hatred. Second, as Charlene Sul explained at a recent meeting, while we all have varying degrees of exposure to indigenous practices, if we approach them with respect and honesty that comes from the heart, the practices can serve to ground us in very important ways. In several meetings, these practices have seemed to serve almost as the groundrules that have made our meetings so effective. In the end, this is, as it should be, just the beginning of a muchneeded, in-depth exploration of the contradictions facing Chicanas/os who strive for revolutionary change in the 21st century.

to connect with people in a way we had not done because many of us had been masking feelings out of respect for what we felt was the good of the group.

As we could see ourselves moving toward some preliminary closure, Delfina Landeros, the woman who had said the "Our Father," made a suggestion that read the needs of the group brilliantly. ${ }^{12}$ She asked that we break into small groups of two or three and share our feelings and ourselves. When we regrouped after about 15 minutes, the room was transformed. There was a trust and a commitment to each other that transcended our shared commitment to our raza students, expressed during the previous days. People explained that while they had initially resisted acknowledging and discussing the tension, they came to see how necessary that work was for us. In the final evaluations for the Institute, the vast majority of participants explained that this was the most important and powerful experience of the entire three 
days. This session helped us understand the final piece to our educational model.

Monica: Knowing that a group like MAESTR@S exists and having experienced what it is about has renewed my hope for the future education of our Chicano youth. A specific discussion during the MAESTR@S Institute was particularly helpful in renewing this hope for me. The discussion was focused on the conflict that arises, specifically within our culture, between Catholic ideology and indigenous ideology.

This issue was not addressed because it was on the agenda, but rather because it became an issue among our group. I have been in "progressive" circles in which Christianity is scorned. Likewise, I have been in Christian circles where non-Christians were harshly criticized. Religion is a controversial topic, to say the least. Naturally, asking a group to recite the "Our Father" outside of a church could cause tension.

The morning of our last day together as a group, Marcos and Margaret addressed the tension related to the "Our Father" prayer. This intense discussion led the group to cross a boundary; a boundary that I perceive to exist between people's general thoughts and ideas and people's deeper personal feelings. Addressing the feelings behind the tension was quite difficult, and initially more tension resulted. Openness forced us to deal with a difficult issue and created an uncomfortable situation. It may have been easier for Marcos and Margaret to avoid this issue, but because they didn't, a valuable lesson was taught and learned. In my own work as a teacher, I will remember how important and effective communication is and that true acceptance requires openness.

After the discussion, I felt that there was a general agreement of acceptance, and I truly felt closer to this group of people who shared their personal thoughts. Whether or not we should pray together, and how or when we should pray may be debatable, but addressing people's feelings about this issue is a step toward a solution. And so, it was not that we reached a resolution that inspired me but rather that so many people shared their conviction to accept people with different faiths as their allies.

Ray: The MAESTR@S Summer Institute was a shot in the arm for any educator of raza youth. It provided tested and proven materials and methods for use in the classroom and an opportunity for those of us "in the trenches" to foster a network of educators who are focused on providing students an education that at once is intellectually challenging and spiritually stirring.

Nadine: I think I left [the Institute] with more questions than answers. What I mean by this is that I think I have (somewhat) of an understanding of the problems and issues [facing] Chicano/a students. I'm still not sure about how to address them though, that is, the actual "nuts and bolts" of $L a$ Raza pedagogy. I think things like MAESTR@S is a start, but to be honest, I'm still struggling on how to put theory into practice and ideals into reality.

Margaret EMarcos: In MAESTR@S we strive to be subversives, to disrupt normal educational processes. While it is difficult to demonstrate this kind of work in an essay, at least three examples in this section demonstrated some of how we do this.

First of all, we interrupt the "normal" educational flow whenever issues arise that are critical to addressing the needs of participants. We modeled this by including a "Timeout" simply because we could not continue in the typical narrative without confronting the challenges of indigenismo in Chicana/o educational work.

Secondly, we integrated the ideas of participants in the article itself through Monica's, Ray's, and Nadine's input. We recognize that regardless of where we are as facilitators or where we might hope people will go through our group work, the reality is that each person is in his or her own unique space, and we have to strive to understand that. Monica helped us see how important the conflict was, while Ray allowed us to see the need for specific models, and Nadine showed us the need for clarity.

Last, and probably most important, we look for ways to hone in on the contradictions that define the experiences of raza in the U.S. and attempt to dissect them with participants. By being a twice conquered people who are both psychologically and physically targeted in the U.S. today, raza must deal with, as just one example, legally being "white" but being racialized as indios (which is deemed a bad thing by the mainstream), although we are indios who have often lost our indigenous culture and have seen it replaced by a culture that is part myth and part sedative, and yet still encompasses aspects of indigenismo that are rich in power and possibility. Focusing on these conflicts allows us to expose the deep ideological work we are doing and push everyone's consciousness, including our own, into new spaces.

These ideas are only part of an explanation of the way in which MAESTR@S engages in revolutionary educational work. It took us a lot of thinking and two days of meetings before we could put all the pieces together after the Institute was over. What follows is our effort to explain that model. What is most essential to understanding the model is that it is neither a prescription nor a formula, but organic and always evolving. It is not something we picked up from books or teacher educators, but is an accumulation of wisdom and learning that has come to us through many channels: our own schooling, our education from our families, our classes and students, our failures, our hearts and spirits, and often through twists of fate that we could have never planned. 
FRAMING MAESTR@S WORK AS A MODEL AND ETHIC

\section{Toward a Model for Revolutionary Education: Margaret and Marcos}

While our work has naturally evolved over the last two years, we have begun to clarify it into a general model. Our primary objective is to erase the norms of educational practice that have been implanted into our minds and practices through dominant ideologies. As we do that, we are trying to nurture a new form of consciousness, in which we use education to pursue sovereignty as we rely on raza ways of learning. Our hope is that this will lead to multiple forms of radical, transformative education work. What follows are some of the key aspects of this process.

Participant input: Our process begins by asking people to come together based on their commitment to an issue, and asking for input in defining and addressing the issue. People know from the start that their input is essential to the process. As the planning continues, participants are constantly updated and always asked for additional contributions.

The content of the sessions comes from the shared vision of people who come from alternative spaces and engage in their work in creative ways that are not always fostered in more conventional educational settings.

Introducing holistic education early-Welcoming rituals: The sessions begin with an indigenous welcoming. It is something that our participants bring with them and share. What is most essential is not what is said or by whom, but challenging conventional notions of education and knowledge and suggesting that education has to be holistic. It has to include our spirits, our families, our histories, our hearts.

Everyone who participates must also realize the importance of each group member. In the introduction, we ask people to share what they have to offer, and we also encourage them to acknowledge who they bring with them, from children to grandparents who have passed on. We strive to expose how important it is to us that knowledge is co-created and that as individuals we represent families and communities that share wisdoms that we live on a daily basis.

Working circles: This work is always done in a circle. Newcomers often initially sit outside of the circle and we ask them to join us as a means of creating community, demonstrating a lack of hierarchy, and attempting to engage everyone. We are assertive about keeping the group seated in a circle and at times, interrupt the conversations to add chairs and expand the circle in order to see one another's faces and eyes.

Setting ground rules: Suspend judging and surrender: Our work always demands demonstrating and living lessons rather than explaining them, but at times we make central ideas overt. For example, we explain the ground rules under which we work and ask for comments and other suggestions. The cornerstone to these ground rules is the importance of a shared understanding that we are all teachers and learners, and that we come together to learn from everyone. We ask people to avoid speechmaking and ego-stroking commentaries as well as excessive complaining about or arguing over issues. Our respect for these goals translates into a respect for each other and a means of functioning in our gatherings. Margaret framed this as "listening with soft eyes," whereby we acknowledge and seek to move together beyond our differences. This requires suspending blaming to seek deeper understanding that can be transformative.

Surrender becomes synonymous with education in our work, beginning with our surrender, as facilitators, to the needs and interests of participants. Our understanding is that the group, together, will develop a plan that is far more complex and appropriate to our needs than any of the facilitators could create before the meeting.

Focus on group dynamics: While we surrender to the group, we also require that they surrender to our effort to challenge them and expose our own limitations in the process. We note gender dynamics, who is dominating or interrupting the discussion, which are the dominant voices, where the silences in the room are, how we occupy space, how space occupies us, and how we use language. We comment on each other as facilitators and the way we use specific techniques for demonstrating our principles: the role of silence, the use of bilingualism, the importance of storytelling and problem-posing as education, the intentional ambiguity of the task-specific work we ask them to do, the necessity of monitoring the emotional temperature of the room and responding to participants/groups and their energy levels, interactions, needs, and frustrations (including their physical needs for food, air, and movement), and the periodic need to engage in agenda setting and schedule revisions with the group.

Emphasize process as product and the critical role of context: In the end, this all amounts to our emphasis on understanding the necessity of process as product and process over content, as we push participants not just to hear the lessons on process but to live them. Still, we also recognize the enormous amount of intellectual and psychological work that goes on in MAESTR@S and so we attempt to frame, name, and interpret that work for participants, particularly at the end of our sessions. We use our content work as a means of exposing the key lessons we develop as a group and urge them to share others as we are invariably introduced to critical lessons we never saw. The focus of participants' attention, at least initially, is always on the content-that is, how to use pop culture, sample courses, methods for developing alternative curricula and the like, which are all cutting-edge and inspiring. 
Yet most of that content cannot be directly translated to another context and implemented immediately. First of all, the experiences and needs of students will be different, not simply in different areas but in different classrooms in the same school. Secondly, as educational facilitators, teachers each have their own strengths and weaknesses and they have to address both as they engage in their work. Our goal, therefore, is not to provide something that people can just walk away and do. Rather, we use the individual workshops to demonstrate the MAESTR@S model by implementing the process and urging participants to develop their own context-specific content and approach. So these workshops define the problem (but do not dwell on it), demonstrate a solution, rely on what the participants bring, assign work to groups, and develop both new ideas and new ways in which to do the work being described.

Rely on youth: Our most successful workshops have tended to be those led by young people, many of who are not teachers and some who are still students themselves. These educational visionaries are effective precisely because they challenge educational traditions in often extreme ways and they think outside of the educational box. Because they often come from innovative intervention programs, they exhibit the freedom they are given to be creative. It has been critical to engage individuals who are willing to push the boundaries of our notions of "professional development" and who accept the basic idea that educational revolution is needed and possible.

Embrace discomfort and expect conflict: Radical education work requires continually attacking our fears. It embraces discomfort and recognizes that discomfort allows people to question those assumptions we understand as norms and to push our thinking into new places. Discomfort demands commitment as part of education work and, in the end, it embodies a sense of trust that participants cannot access in its absence. In the end, this education work, through the use of discomfort and confronting conflicts, becomes community building and in so doing creates networks of learners with a shared revolutionary consciousness who can apply their combined power to their educational work.

\section{The MAESTR@S Ethic}

Marcos: Just before the Summer 2001 Institute, Margaret explained that she saw MAESTR@S as an ethic. It was not content or even specific methods but rather an ethic for doing educational work that challenged the mainstream approach to schooling. This ethic becomes the key foundation to establishing a shared revolutionary consciousness. Margaret's insight allowed us to put into words all of the things we had been doing as well as to frame the key ideas that constitute that ethic.
Margaret E Marcos: Respect and love students: Ché Guevara said that the most critical weapon in any revolution is love (Guevara, 1967). The educational revolution that we envision is grounded entirely in our love for the raza youth of our communities. The students who were mentioned at the start of this piece were all children that Marcos loved. It was from this love that his passion to help them empower themselves came. Furthermore, this love meant that he respected these students and trusted in their insights, power, and abilities. We have to love all of our students. As with our own children, we may not always like them or the things they do, but we have to love them. ${ }^{13}$

Cultivate trust: Trust, then, is the next essential ingredient to our ethic. Not only do we have to prove to our youth that they can trust us, but we have to trust them so we can learn from them and so that they can have models to help them learn to trust themselves. Because we as facilitators share this love and trust, for example, we are able to surrender to each other and know that the other will take us to places that we need to go, but would have never gone alone.

Build on familia, comúnidad, historia, and raza wisdom: Our love emerges from our own histories and families. As our families and communities emphasize the need to be bien educada/o, we look at the complex knowledge systems in these communities for the lessons as to how we must do our educational work. This requires holistic educational approaches that integrate mind, body, heart, and spirit. We look to youth, to the arts, to families, and to the streets for new ways to engage in our educational work. We understand our history so that we can transcend the vicious cycles in which we have been caught. We understand the power of racism, sexism, homophobia, and capitalism, only so we can offer alternatives that emerge from their absence rather than as a simple response to them. We are subversives who seek Chicana/o educational selfdetermination through claiming the sovereignty of our minds.

Speak "revolution" so as to be revolution: Finally, we speak in a language of revolution because it is the first step to living that revolution. It names a possibility and an aspiration while our actions create a concrete, albeit tentative, vision of that eventual reality that we then live on a daily basis.

These are the components that we now understand to make up the organic and evolving MAESTR@S ethic. Our approach fits nicely into the framing idea that María Alaniz shared with us at the November, 2001 MAESTR@S Encuentro when she said that "Teaching is a sacred act!"14 In a different context, Vinicio Rubalcava went further to explain that our classrooms must be sacred spaces. ${ }^{15}$ 


\section{Living Educational Revolution: Margaret \& Marcos}

We have attempted to define our work, encapsulating our approach and ethic, as Raza Studies. We adopted this label because some of our members were using this as a way of acknowledging that they were not doing the typical Chicana/o Studies work and that they were working with diverse populations that also included other Latinas/os. For MAESTR@S, Raza Studies transcends pedagogy and curriculum, going beyond approaches to learning and toward approaches to living. The whole person (students and teachers) enters the classroom and that is who must teach and who must learn. We have developed an understanding of these notions that goes beyond simple effective practices for students in general to organize something specific to raza communities:

Raza Studies is holistic education [emphasizing mind, body, heart, and spirit] in which we meld methods, content, identity issues, policy/political struggles, $f a-$ milia, comúnidad y historia, via student-centered (contextspecific), spiritually-principled, problem-posing that is based on community service learning/collaboration and develops organizing skills. This is grounded in raza wisdom, raza ways of knowing, and seeks a new form of literacy - raza literacy. Raza literacy is based on an understanding of the wisdom that has been passed on in our communities for thousands of years. It includes the analysis of life ways [philosophy, religion, math, letters, science, and the arts] through raza history. ${ }^{16}$ We recognize that from this world-view raza history is dynamic. We are history as we live with ancestors, descendants, and living families simultaneously. This understanding is a central component to raza wisdom.

While the MAESTR@S process and ethic present visionary, sometimes intangible, approaches to learning, we have attempted to demonstrate how MAESTR@S provides a practical way of transforming teaching in institutions that resist change. While others throw up their hands and complain about the system,MAESTR@S provides a subversive means of sharing empowering education with raza youth. As Julia Gonzalez-Luna explained at one of our recent encuentros, MAESTR@S demonstrates a way of matching revolutionary words with actions. ${ }^{17}$

MAESTR@S' work begins with the understanding that the dramatic schooling conditions faced by raza youth demand an educational revolution. The first step in this revolution is to upset standard thinking and practice in education. Once the oppression inherent in these practices and ideologies is exposed, we move to erase them from our lives-not that we pretend that they do not exist but rather that we choose not to respond directly to them and instead replace them with revolution- ary work. The next step in this process then is to foster a new and revolutionary consciousness among educators, by nurturing the ethic described above. That new, collective consciousness allows us to then assert our moral authority to transform education, as the mujeres of Cihuatl Olin have so powerfully done! Finally, we have to create revolutionary educational practice. We argue not for formulas but instead for constant innovations grounded in the tremendous possibilities of raza wisdom and teaching that is holistic and focuses on the body, mind, heart, and spirit simultaneously. The strength of this work is that it strives to create collectives of radical thinkers with a revolutionary consciousness whose power increases exponentially through the community we create.

In the end,MAESTR@S is simply an idea, lived. Because it can be lived, it allows us to imagine and then pursue a different world. Most importantly, as we pursue it, we will create new and powerful opportunities for all of the Miguel Sanchezes who are currently being pushed out of schools across the country.

The daily lives of raza youth demand that we transform our work in education. They need researchers who engage in social justice work. They need researchers who use their publications and research to move toward concretely addressing the problems they regularly face. This work, therefore, ends with a call for researchers and journals to use their work to engage in social justice, acknowledging that the blind and naïve belief in the need for their objectivity in fact typically reaffirms and supports a status quo that is waging war against raza youth and other working class students of color.

\section{A Final Note to You, the Reader}

MAESTR@S seeks to transform how we all approach education work. In this writing we have sought to provide you with a means of participating in this process. We have taken several steps that we believe any reader can apply to work in any context:

- It is essential that we challenge educational conventions, including what we consider legitimate educational knowledge and discourse. This can be done in multiple ways: transforming the language we use in education work to one of revolution, creating new norms for educational work (e.g., replacing "standards" such as objectivity and teacher-centered schooling), and looking toward alternative forms of constructing education (such as raza-centered pedagogy).

- The central component in developing empowering educational processes with raza youth is emphasizing the primary role of process itself. Schooling is increasingly focused on content as central, but raza ways of knowing and constructs like educacion tell us that, in the end, education is really about learning processes of empowering ourselves 
and transforming society for the better. We have developed steps in this process, but more important than the steps is realizing this idea of the centrality of process over product or content.

- Achieving educational practice that allows raza and other youth to empower themselves demands a revolutionary ethic. Although this ethic may be defined differently in unique contexts, it is grounded in the two ideas discussed above and on the understanding that the revolution we seek is grounded in a radical understanding of love.

- All of this work demands radical, revolutionary, educational consciousness raising.

We know some readers will create new meanings out of this work, others will struggle to make meaning out of it, and some will reject the meanings we seek to make. We engage in this work as part of a community instead of "for" a community that has no input on the work. Rather than telling you what we want you to know now, we look forward to seeing you build on this work and teach us and others in the future. ${ }^{18}$

\section{NOTES}

1. We have deliberately created this term MAESTR@S to name our group because it is a visual intervention and a recoding of information. For a related reason, we are also importing Spanish words into the article. We seek to augment the visual cues to the reader to illustrate that we are moving between different linguistic, epistemological, and ideological systems. At times, though, the words impede our ability to communicate textured and subtle meanings. "Maestros" is one example. We resist using Maestros because of the male-gendered meaning that is embedded within it and we think the other convention "maestros/as" can be cumbersome. Consequently, we have chosen to use this symbolized word. We are not completely satisfied with MAESTR@S as a neologism because the "o" engulfs, and some might say dwarfs, the "a" in the symbol but we settled on it, cognizant that it provides us with more to reflect on about the relations between the genders. Finally, we have also chosen to speak the word as "maestras."

2. Throughout this article we have chosen to use the word raza to identify both ourselves as certain types of educators and the Latina/o youth who are the focus of our work. Raza literally means race. It is used among Chicanas/os and Latinas/os simply to refer to Chicanas/os and Latinas/os as a group. Some use the term to refer to people in their neighborhood, others to refer to Chicanas/os, and others as a pan-Latina/o label. We chose to use this term because it is commonly used within Latina/o communities despite the different, formal labels used by individuals. This word is also deliberately and carefully chosen because of the historical, linguistic, racial, cultural, and ideological meanings layered within it. Our work takes into account such issues as the conflicting histories of different regions of Latina/o peoples, the pain of language loss as English replaces Spanish, as well as the many cultural characteristics, such as accents or clothes, that have been given racial significance in order to devalue our communities. This article does not explore nor expose all of those assumptions or premises. The term will be discussed more later in the article.

3. Paulo Freire (1970) used this term to refer to the consciousness-raising that must take place in doing radical education with disenfranchised communities. He was referring to a process of helping these communities expose and deconstruct the social injustice that leads to their oppression. We similarly use the term to reflect the consciousness-raising we strive to do in all of our work. Our goal is to make these ideas clear by the end of the article.

4. As you will soon discover, we strive to develop processes for educational empowerment rather than simple content that has radical leanings.

5. The term "elders" refers to the many who have come before us and from whom we have learned. The word is chosen with some humility; acknowledging that we all have much to learn from those who are educated formally as well as those who have learned their lessons by living thoughtful lives devoted to improving conditions for their families and their communities.

6. Please see Telling to Live (Latina Feminist Group, 2001) for a powerful, innovative model of this idea and of the approach we are discussing. As this note demonstrates, we do occasionally make references to point you to elders and others who share some of the deeper wisdoms that inform our work.

7. This is a collaborative project. Marcos was the spark behind it and also organized this piece. The introductory sections were written from his perspective (although Margaret's work was a strong influence and serves as the rationale behind the project). The work on our educational model was done by Margaret and Marcos together, much of it grounded in Margaret's ground-breaking LatCrit work as well as the insights we have picked up from the group at our encuentros. Many people have contributed to the work we have done. We have included as many as possible by asking participants to share their thoughts. Their voices and contributions are interspersed throughout the piece. Monica, Ray, and Nadine, for example, each made important written contributions, but only worked on their specific contributions in the development of this essay.

8. This is an idea we adapted from something Cherrie Moraga said in a recent interview. "The most radical of our people of color movements still talk about sovereignty-even if it's just sovereignty of the brain, I mean sovereignty in terms of your real identification with the United States of America." (Reyes, 2001, p. 35)

9. Cihuatl Olin Nauhcampa means the Women's Movement of the Four Directions in Nahuatl, an indigenous Mexican language. They are made up of Jenny, Lorena, and their compañeras, Dina Suarez and Ursula Loret de Mola. Each of them has been involved in MAESTR@S since very early on, which led to the development of their own group. Their work will be discussed throughout this article.

10. Lidia created and still directs an alternative school designed to meets the need of raza in the San José area.

11. We understand that "surrender" is a loaded word so we will try to explain it. We have found that teaching together brings different forces into the classroom. We can't anticipate what the other person is going to say or do so we have to give up control. We depend on being able to build on the unexpected. Thus, we try to de-center ourselves and instead center 
the work we are doing. We "surrender" to the dynamics of the group and trust that together we will maintain an effective environment.

12. Delfina is a teacher in Tucson whose only work with MAESTR@S came at the Summer Institute. Her contributions were pivotal to the Institute.

13. Marcos: I recently heard this idea conveyed by a Native American elder, Uncle Harold Belmont, who described this idea as central to our work in education.

14. Maria is a Professor of Social Science at San José State University and does a lot of work training future teachers. She has attended a few of our meetings. She said she was building on ideas she picked up from reading bell hooks' work.

15. Vinicio was a student in a class with Marcos in the spring of 2002.

16. The most vivid example of this has been how Cihuatl Olin Nauhcampa has developed standards-based, K-2 curriculum by using the medicine wheel and indigenous concepts.

17. Julia coordinates an after-school program designed to address the needs of at-risk youth in the northern part of the Bay Area. She has been to most of our meetings, has hosted an encuentro for the group, and led workshops for us.

18. We urge people who are interested in this work to contact us, to act on it, to share new ideas with us, and to look for others who can help you engage in this kind of work. MAESTR@S continues to have meetings and Institutes and is always looking for new participants and presenters. We can be reached at pizarro@email.sjsu.edu and montoya@libra. unm.edu

\section{REFERENCES}

Californians for Justice Education Fund. (2001). Still separate, still unequal: A look at racial inequality in California schools 47 years after Brown v. Board of Education. Oakland, CA: Author.

Delgado, R., \& Stefancic, J. (Eds.). (1998). The Latino/a condition: A critical reader. New York: New York University Press.

Freire, P. (1970). Pedagogy of the oppressed. New York: Continuum.

Gonzalez, N., Moll, L., Tenery, M., Rivera, A., Rendon, P., Gonzales, R., \& Amanti, C. (1995). Funds of knowledge for teaching in Latino households. Urban Education, 29(4), 443-470.

Guevara, E. (1967). Ché Guevara speaks: Selected writings and speeches. New York: Pathfinder.

Latina Feminist Group. (2001). Telling to live: Latina feminist testimonios. Durham, NC: Duke University Press.

Reyes, R. (2001, Summer). After the war years: Cherrie Moraga reflects with Rosi Reyes on 20 years of living and writing from a place of contradiction. ColorLines: Race, Culture and Action, 4(2), 33-35.

Romero, M. (2000). Historicizing and symbolizing a racial ethnic identity: Lessons for coalition building with a social justice agenda. 33 U.C. Davis Law Review 1599.

Valenzuela, A. (1999). Subtractive schooling: US-Mexican youth and the politics of caring. New York: State University of New York Press.

Wells, F. (2001). ZIP codes shouldn't determine our students' future [On-line]. California Educator, 5(8). Available: http://www.cta.org/cal_educator/v5i8/feature_zip. html

\section{APPENDIX A: BACKGROUND INFORMATION ON MAESTR@S}

\section{Mission}

-MAESTR@S [including students, teachers, parents, and communities] will work to empower ourselves as individuals and gain voice in the educational system. Our objective is to achieve educational self-determination: shaping new strategies for "educating" raza youth.

- In this effort, we will define our own terms in the struggle for empowerment and self-determination. In short, we will develop and implement a proactive agenda for raza education rather than a reactionary one (moving beyond resistance, prevention and the constraints placed upon us by the educational mainstream). This work must be innovative and will be grounded in raza "funds of knowledge" (e.g., employing raza belief systems and forms of knowledge in the development of teaching methods).

- We will strive to keep control and ownership of this struggle in the hands of the youth, which will serve as the foundation for the teaching revolution we are pursuing.

\section{General Goals}

- Develop curricular and pedagogical change that will help raza youth to educationally empower themselves.

- Ground this work in the recognition that students and their families bring powerful resources to their schooling.

- Provide an avenue for teachers to discuss and address these issues (rather than being talked to) and to develop a working network of individuals committed to these goals.

- We frame this work under one goal: Taking Raza Studies to the Streets and Bringing the Streets Back to Chicana/o Studies. This idea embodies our efforts to bring Radical Raza Studies work directly to the youth and to take current and pressing issues facing youth back to Chicana/o Studies in the university so that we can develop informed practices that have revolutionary possibility. We provide activist/organizing training, collaboration and networking.

\section{Specific Goals}

- Teacher Education/Professional Development: Innovative Teaching Methods

- Teacher Education/Professional Development: Innovative Curricula

- Teacher Empowerment and Recruitment

- Parental/Community Empowerment

- Student Empowerment

- Implementation Strategies and Plans for Raza Studies in the High Schools 
- Critical Educational Analysis

- Facilitating Networking of Individuals Committed to our Goals

- Developing an Internet Clearinghouse of our Work

Marcos Pizarro is an Assistant Professor of Mexican American Studies at San José State University.
Margaret Montoya is Professor of Law at the University of New Mexico School of Law.

Monica Nañez is a recent graduate of San José State University.

Ray Chavez is the former director of the Hispanic Studies Department at Tucson Unified School District and is in a doctoral program at the Harvard University Graduate School of Education.

Nadine Bermudez is completing her Ph.D. in the School of Education at UCLA. 